\title{
Methane coupling over magnesium oxide: how doping can work
}

\author{
Pierre Schwach, Marc Georg Willinger, Annette Trunschke*, and Robert Schlögl
}

\author{
Dedicated to Prof. Dr. Drs. h.c. Helmut Schwarz on the occasion of his $70^{\text {th }}$ birthday
}

Functionalization of methane remains a challenging target from academic as well as industrial point of view. ${ }^{[1]}$ New concepts in catalytic activation of $\mathrm{C}-\mathrm{H}$ bonds are needed ${ }^{[1 \mathrm{a}]}$ to overcome the current limitations in selectivity, which hamper the broad application of methane coupling in the production of olefins as important platform chemicals from sustainable resources like natural gas or organic waste. Among the various inorganic materials that have been evaluated as heterogeneous catalysts for oxidative coupling of methane (OCM), alkaline earth oxides doped with alkali elements or transition metal ions received particular attention. ${ }^{[2]}$ High reaction temperatures (973-1273 K) are needed. However, the temperature is not required for $\mathrm{C}-\mathrm{H}$ activation that may aided by coordinatively unsaturated sites already at low temperature, ${ }^{[3]}$ but rather for recovery of an active catalyst surface free of hydroxides and carbonates. Under the harsh reaction conditions, oxide catalysts, like $\mathrm{Li}-\mathrm{MgO}$, undergo fast deactivation due to sintering promoted by water as an unavoidable reaction product. ${ }^{[4]}$ Oxygen or magnesium vacancies $\left(V_{O} \cdot, V_{M g}\right)$ are involved in the sintering of $\mathrm{MgO}$ by facilitating reconstructions due to enhanced diffusion of lattice ions, which is fast in any case at such high temperatures. ${ }^{[5]}$ On the other hand, vacancies may have an impact on activity and selectivity in catalysis. However, point defects were so far never detected under realistic OCM working condition over $\mathrm{MgO}$.

In a recent study, Freund et al. provide evidence that strongly bound $\mathrm{O}_{2}^{-}$species as precursor of dissociatively adsorbed $\mathrm{O}_{2}$ are formed on highly ordered $\mathrm{CaO}$ films doped with $\mathrm{Mo}^{2+}$. The results indicate that molecular activation on doped oxides does not require any surface structural defects. ${ }^{[6]}$ Accordingly, it is suggested that activation of methane on smooth surfaces of transition-metal-doped wide-gap oxides may involve such activated oxygen species.

In the present work, we put the concept to test and synthesized powder catalysts, working at $\mathrm{T}=1023 \mathrm{~K}$. We used doped magnesium oxide as it was frequently investigated in OCM. ${ }^{[7]}$ Pure magnesium oxide deactivates at this temperature quite fast and reaches a stationary state after a few minutes to several hours depending on

[*] P. Schwach, Dr. M. Willinger, Dr. A. Trunschke, Prof. Dr. R. Schlögl

Department of Inorganic Chemistry

Fritz-Haber-Institut der Max-Planck-Gesellschaft

Faradayweg 4-6, D-12489 Berlin (Germany)

E-mail: trunschke@fhi-berlin.mpg.de

Homepage: http://www.fhi-

berlin.mpg.de/acnew/welcome.epl

[**] The authors thank M. Hashagen, F. Rybicki, Dr. F. Girgsdies, Dr. Maik Eichelbaum, and Dr. O. Timpe for experimental support and scientific discussion. This work was conducted in the framework of the COE "UniCat" (www. unicat.tu-berlin.de) of the German Science Foundation

Supporting information for this article is available on the WWW under http://www.angewandte.org or from the author. the applied contact time and the initial nano-structure of the magnesium oxide. In the stationary state, a low, but constant yield of the coupling products ethane and ethene is obtained over smooth, rounded $\mathrm{MgO}$ particles. ${ }^{[8]}$

In this contribution, we introduced $\mathrm{Fe}$ in ppm quantity into $\mathrm{MgO}$ The synthesis of Fe-doped polycrystalline magnesium oxide in which the Fe dopant is homogeneously distributed over the entire bulk is, however, quite challenging and requires highly sensitive analytical techniques for verification. The issue is dissolving the dopant in such a way into the bulk of the $\mathrm{MgO}$ that no precipitates or segregated nanostructured dopant phases occur during the drastic reaction conditions. Only then the validity of the electronic doping concept put forward by Freund et al. can be tested without interference for other catalytic actions of secondary phases.

The presence of $\mathrm{Fe}$ atoms on the surface may introduce additional redox chemistry into the activation mechanism of methane, but, even in an ideal solid solution, terminating Fe atoms cannot be avoided. Therefore, the $\mathrm{Fe}-\mathrm{MgO}$ catalyst was modified by subsequent adsorption of highly dispersed gold on the surface. An $\mathrm{Au}-\mathrm{MgO}$ catalyst ${ }^{[9]}$ was included in the study for reference.

Table 1. General characteristics of the doped $\mathrm{MgO}$ catalysts and normalized formation rates of coupling products ethane and ethene in OCM of methane.

\begin{tabular}{cccc}
\hline Catalyst & Fe-MgO & Au-Fe-MgO & Au-MgO \\
\hline $\mathrm{ID}^{[a]}$ & 14696 & 14593 & 14588 \\
$\mathrm{C}_{\mathrm{Fe}}^{[\mathrm{b}]}[\mathrm{ppm}]$ & 654 & 402 & - \\
$\mathrm{a}^{[\mathrm{c}]}[\AA]$ & $4.214(1)$ & $4.213(1)$ & $4.214(1)$ \\
$\mathrm{L}_{\mathrm{Vol}} \cdot \mathrm{I} \mathrm{B}^{[\mathrm{c}]}[\mathrm{nm}]$ & $46(1)$ & $67(1)$ & $47(1)$ \\
$\mathrm{A}^{[\mathrm{d}]}\left[\mathrm{m}^{2} \cdot \mathrm{g}^{-1}\right]$ & 32.0 & 19.9 & 25.6 \\
$\mathrm{r}_{\mathrm{C} 2+}{ }^{[\mathrm{e}]}\left[\mu \mathrm{mol} \cdot \mathrm{s}^{-1} \cdot \mathrm{g}^{-1} \mathrm{cat}\right]$ & 5.12 & 13.55 & 0.68 \\
$\mathrm{r}_{\mathrm{C} 2+}{ }^{[\mathrm{e}]}\left[\mu \mathrm{mol} \cdot \mathrm{s}^{-1} \mathrm{~m}^{2}\right]$ & 0.16 & 0.68 & 0.03 \\
Redox active $\mathrm{Fe}^{[\mathrm{f}]}$ & $6 \%$ & $7 \%$ & - \\
\hline
\end{tabular}

[a] Catalyst ID for clear identification of the batch. [b] Measured by AAS. [c] Determined by XRD. [d] Specific surface area calculated applying the BET equation. [e] Measured after 4 hours time on stream; Reaction conditions: $\mathrm{T}=1023 \mathrm{~K}, \mathrm{~W} / \mathrm{F}=0.033 \mathrm{~g} \cdot \mathrm{s} \cdot \mathrm{ml}^{-1}$, $\mathrm{CH}_{4} / \mathrm{O}_{2} / \mathrm{N}_{2}=3 / 1 / 1$. [f] Percentage of $\mathrm{Fe}$ that is accessible at the surface as estimated by temperature-programmed reduction (see Tab. S1).

The catalysts were synthesized by hydrothermal treatment of $\mathrm{MgO}$ in presence of aqueous solutions of $\mathrm{FeSO}_{4}, \mathrm{HAuCl}_{4}$, or a mixture of the two solutions, respectively, in a microwave autoclave at $483 \mathrm{~K}$ and 10 bar for 3 hours, followed by annealing in flowing Ar at $1173 \mathrm{~K}$ for 3 hours. In order to remove potentially segregated transition metal and metal oxide particles, the obtained solids were subjected to a treatment with aqua regia or nitric acid, respectively, and annealed again in $\mathrm{Ar}$ at $1123 \mathrm{~K}$ for three hours. X-ray diffraction reveals that the lattice constants of the three doped catalysts do not vary significantly, but the size of the coherently 
scattering domains (reported from full patterns XRD analysis as volume weighted mean column length based on integral breath $\left.\left(\mathrm{L}_{\mathrm{Vol}} \mathrm{IB}\right)\right)$ differs, showing the largest crystalline domains for Au$\mathrm{Fe}-\mathrm{MgO}$, which is also reflected in the lowest specific surface area (Tab. 1). Structural investigation by TEM reveals typical small aggregates consisting of cubic shaped particles that are intergrown and connected mainly along shared faces (Fig. 1). The domain size determined by XRD is similar for Fe-MgO and $\mathrm{Au}-\mathrm{MgO}$ (Tab. 1) and ranges between 5 and $100 \mathrm{~nm}$ according to TEM (Fig. 1). The slightly lower specific surface area of $\mathrm{Au}-\mathrm{MgO}$ indicates a smoother surface of the gold-covered $\mathrm{MgO}$ compared to Fe-MgO.

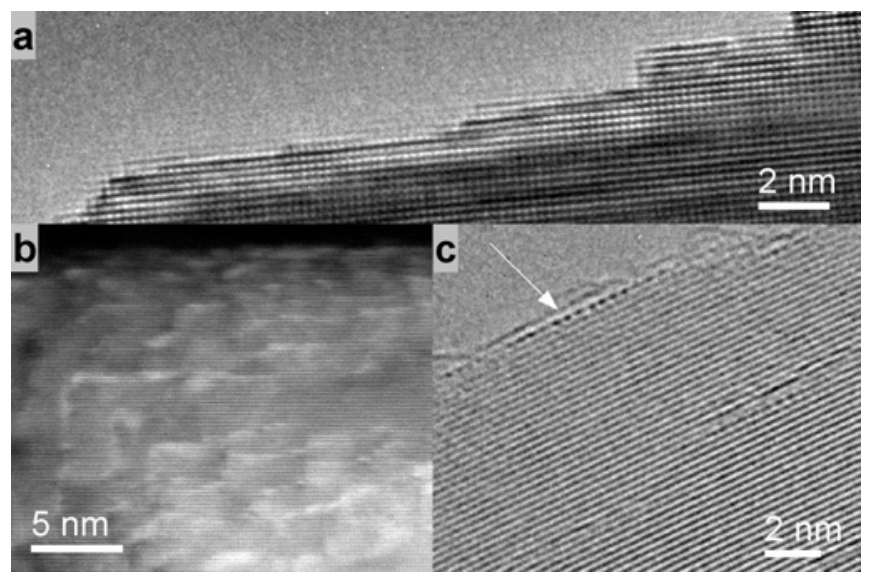

Figure 1. a) HRTEM image showing the stepped surface of Au-FeMgO. b) HAADF STEM image with characteristic bright contrast at steps and edges due to decoration with heavy atoms. c) Columns of heavy atoms can also be seen in thin regions in HRTEM.

The UV-vis spectra of $\mathrm{Fe}-\mathrm{MgO}$ and $\mathrm{Au}-\mathrm{Fe}-\mathrm{MgO}$ are dominated by an intense absorption in the range of ligand to metal charge transfer (LMCT) bands (Fig. S1). The absorption maximum near $288 \mathrm{~nm}\left(34723 \mathrm{~cm}^{-1}\right)$ is attributed to isolated $\mathrm{Fe}^{3+}$ ions in octahedral coordination, i.e., on $\mathrm{Mg}^{2+}$ lattice positions. ${ }^{[10]}$ EPR spectroscopy confirms the occurrence of $\mathrm{Fe}^{3+}$ in cubic symmetry sites in $\mathrm{MgO}$ (Fig. S2). Contributions of oligomeric species and iron oxide nanoparticles to the UV-vis spectra cannot be excluded due to the complex fine structure and the extended tail of the bands towards decreasing energy. However, no aggregates of iron have been detected by TEM, indicating high $\mathrm{Fe}$ dispersion. Since the $\mathrm{Fe}$ concentration is low, the weak absorption due to d-d transitions in the range between $330 \mathrm{~nm}\left(30000 \mathrm{~cm}^{-1}\right)$ and $1000 \mathrm{~nm}\left(10000 \mathrm{~cm}^{-1}\right)$ gives featureless, very weak and broad bands that do not allow an unambiguous interpretation with respect to the coordination environment of $\mathrm{Fe}^{3+}\left(\mathrm{d}^{5}\right)$ ions, and potentially appearing $\mathrm{Fe}^{2+}\left(\mathrm{d}^{6}\right)$ ions. The spectra of the gold-containing catalysts exhibit the characteristic surface Plasmon mode around $520 \mathrm{~nm}\left(19230 \mathrm{~cm}^{-1}\right)$ that is ascribed to gold nano-particles. ${ }^{[1]}$ The broad appearance of the band suggests that $\mathrm{Au}$ occurs in different particle sizes ranging from atomic dimensions to Au particles with a diameter of about 10 $\mathrm{nm} .{ }^{[12]}$ Indeed, very rare and scarcely distributed isotropic gold nanoparticles can be found on the surface of the $\mathrm{MgO}$ particles by TEM.

Temperature-programmed reduction (TPR) - oxidation (TPO) cycles have been performed to analyze the redox properties of the Fe-containing $\mathrm{MgO}$ catalysts (Figs. S3-S4). In the first run, the catalysts were heated in inert gas and evolution of hydrogen was observed in a temperature range between 573 and $673 \mathrm{~K}$ and under isothermal conditions at $1073 \mathrm{~K}$ indicating the formation of point defects in the bulk of $\mathrm{Fe}-\mathrm{MgO}$ and $\mathrm{Au}-\mathrm{Fe}-\mathrm{MgO}$ during the thermal pretreatment. ${ }^{[13]}$ The hydrogen-consumption profile of the first TPR run differs from the second and third run that have been performed in each case after intermediate temperature-programmed oxidation. In contrast, the second and third TPR profiles are identical revealing high reversibility, stability and absence of segregation processes after initial stabilization during the first cycle. This applies to Fe$\mathrm{MgO}$ (Fig. S3) as well as to $\mathrm{Au}-\mathrm{Fe}-\mathrm{MgO}$ (Fig. S4) indicating that the catalysts are well comparable, in particular, because the bulk oxide properties, which have been sensed by redox probing, are quite similar in agreement with the XRD results. The first TPR run reveals a dopant-induced difference between the two catalysts. In addition to the two high-temperature peaks around $810-840 \mathrm{~K}$ and $1050-1060 \mathrm{~K}, \mathrm{Fe}-\mathrm{MgO}$ exhibits an additional hydrogen consumption peak at low temperature $(513 \mathrm{~K})$ arising from easily reducible $\mathrm{Fe}$ species. The peak does not appear again in following cycles indicating the dissolution of the species into the bulk where it is protected from re-oxidation. The amount of consumed hydrogen proves that only a minor fraction of the low-level iron doping is susceptible to reduction on the surface (Tab. 1 and Tab. S1) indicating the homogeneous distribution of the dopant within the bulk of magnesium oxide. The fraction of reducible iron is initially higher in $\mathrm{Fe}-\mathrm{MgO}$ compared to $\mathrm{Au}-\mathrm{Fe}-\mathrm{MgO}$, indicating that surface iron species are shielded by topping gold species.

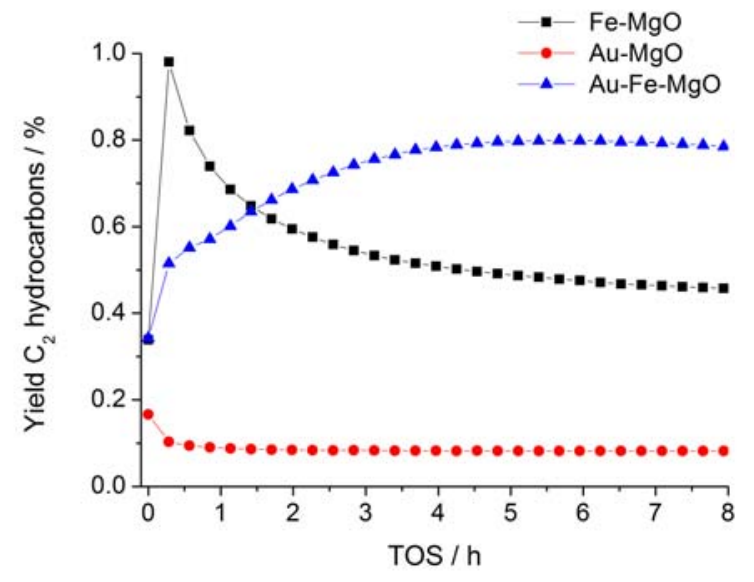

Figure 2. Yield of ethane and ethene in the oxidative coupling of methane as a function of time on stream (TOS) at T=1023 K; W/F= $0.0167 \mathrm{~g} \cdot \mathrm{s} \cdot \mathrm{ml}^{-1} ; \mathrm{CH}_{4} / \mathrm{O}_{2} / \mathrm{N}_{2}=3 / 1 / 1$.

The low yield of coupling products in OCM as presented in Fig. 2 was deliberately measured at short contact times to prevent full oxygen conversion and thus to allow a meaningful kinetic comparison. Gold seems to block the active sites on the surface of $\mathrm{MgO}$ since $\mathrm{Au}-\mathrm{MgO}$ shows only negligible activity. This is ascribed to the propensity of gold to adsorb at step edges of the $\mathrm{MgO}$ and thus covering the active sites related to edges. ${ }^{[14]} \mathrm{Fe}-\mathrm{MgO}$ is more active (Figs. S5-6) and selective (Fig. S7) resulting in higher yield. The start-up behaviour of $\mathrm{Fe}-\mathrm{MgO}$ is attributed to the presence of surface redox-active iron species in accordance with the observations made by TPR. Further increase in methane conversion and selectivity is achieved by co-doping with Fe and Au. Such a synergistic effect of the two transition metal additives becomes even more obvious by comparing the rate of $\mathrm{C}_{2}$ formation normalized to the specific surface area of the catalyst (Tab. 1). After a formation 
period with increasing activity, $\mathrm{Au}-\mathrm{Fe}-\mathrm{MgO}$ shows stable activity at the time scale of the present experiment. This behaviour is surprising and novel for alkaline earth metal oxide-based catalysts.

An explanation may be provided by electron microscopy. HAADF STEM, which is sensitive to variations in atomic weight, allows locating the heavier dopant atoms in the $\mathrm{MgO}$ matrix. As can be seen in Fig. 1, corners and edges are characterized by brighter contrast, indicating the presence of either $\mathrm{Au}$ or Fe. This is confirmed by HRTEM images recorded from thin regions of $\mathrm{MgO}$ crystals, where rows of strongly scattering atoms are detected at surface steps even after catalytic testing (Fig. 1c and Fig. S8). These atoms will suppress the action of steps as active sites and thus poison the $\mathrm{Au}-\mathrm{MgO}$ catalyst that does not have sites caused by electronic doping. In addition, investigation of the bulk structure by HAADF STEM and TEM reveals the presence of local strain, causing particular contrast variations such as indicated in Fig. 3a and $b$, respectively. Analysis of the lattice fringes ${ }^{[15]}$ shows doping induced strain and lattice rotation, as visualized in Fig. 3c and d, respectively. Due to the low concentration, EDX elemental analysis is not sensitive enough to clarify weather the defects are caused by gold or iron incorporation into the $\mathrm{MgO}$ lattice.

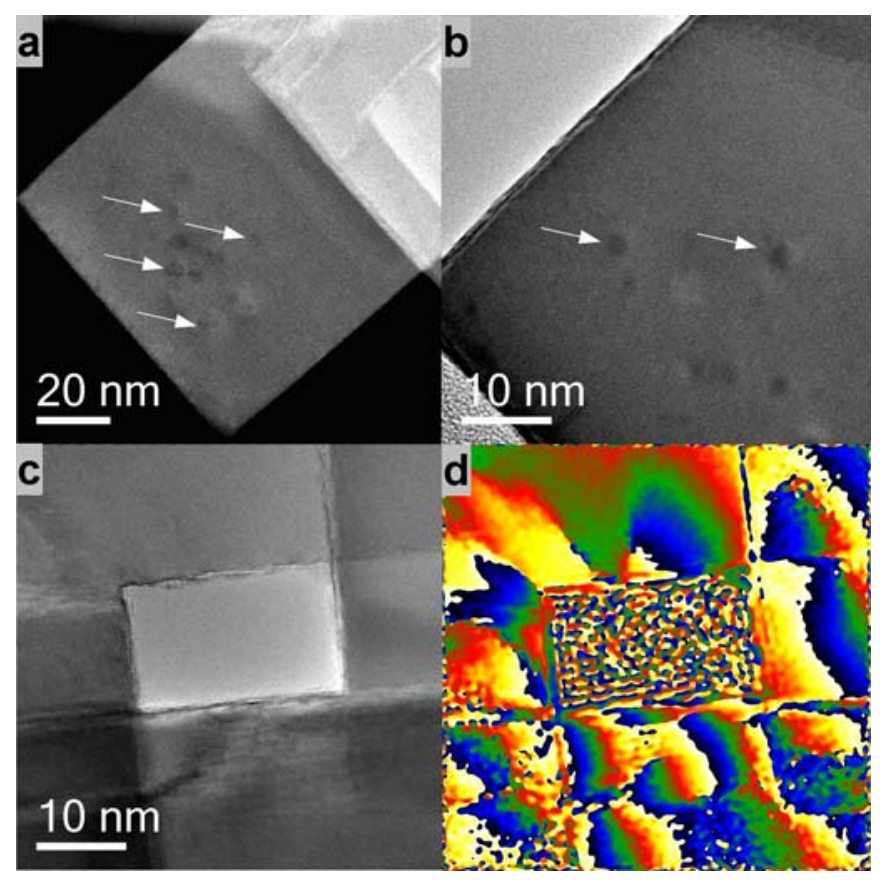

Figure 3. a) HAADF STEM and b) TEM image with localized contrast variations due to defects caused by bulk doping as indicated by arrows. c) HRTEM image of doped MgO particles for which the lattice rotation due to strain is shown in d).

The sintering behaviour of $\mathrm{Au}-\mathrm{Fe}-\mathrm{Mg} \mathrm{O}$ is similar compared to un-doped $\mathrm{MgO}$. Initially, the surface of the cube-shaped particles exposed stepped and atomically flat planes (Fig. 1). Steps are usually in the range of half (one atom) and single unit cell height (Fig. 1a). During catalytic reaction, the abundance of such small steps decreases forming larger steps. Despite these sintering phenomena, the catalytic activity of the $\mathrm{Au}-\mathrm{Fe}-\mathrm{MgO}$ catalyst shows appreciable stability. This is a clear indication that the lasting activity is not due to the conversion of methane at steps but rather at sites located at terraces. Doping has changed the nature of the active sites as indicated clearly by the temporal evolution of the catalytic activity shown in Figures 2 and S5-7. The inverse trend for the codoped system as compared to the other systems points to the formation of active sites for oxygen activation in $\mathrm{Au}-\mathrm{Fe}-\mathrm{MgO}$ during time on stream whereas the other systems deactivate through the loss of monatomic step sites following surface transformation caused by the reaction products water and $\mathrm{CO}_{2}$. The stable minimal activity of the $\mathrm{Au}-\mathrm{MgO}$ system marks the intrinsic activity of active sites in the present $\mathrm{MgO}$ that are not associated with step edges. Compared to this activity (see Table 1 ) the electronic doping by $\mathrm{Fe}$ increases the rate of $\mathrm{C}_{2}$ formation by over an order of magnitude.

For the classical $\mathrm{Au}-\mathrm{MgO}$ system it was found that small doping levels produce metallic and some chemically active gold species decorating steps and thus reducing the activity of parent $\mathrm{MgO}$ exactly as found in the present study ${ }^{[9]}$ Only at much higher doping levels catalytic effects were described and associated with $\mathrm{Au}$ particles and defect formation in $\mathrm{MgO}$. In the present study two types of gold were evidenced based on the catalytic results: In single doped $\mathrm{Au}-\mathrm{MgO}$ only the step-decorating poisoning effect was found Through the presence of sub-surface iron species in the co-doped system the edge decorating effect was massively overruled by a beneficial effect of creating structurally stable novel active sites at terraces of the $\mathrm{MgO}$ without introducing vacancies that may destabilize the system at longer time on stream. This second gold species apparently arises from a significant gold-support interaction achieved by the strain in the $\mathrm{MgO}$ due to iron doping. The possible effects of isotropic unstrained gold particles are negligible in the present study due to their very low abundance as a consequence of the synthesis strategy. Electronic doping of $\mathrm{MgO}$ terraces is also achieved through iron dissolution only, but with significant lower effectiveness. It is tempting to conclude that the co-doping creates highly active sites for oxygen activation into a peroxy-species ${ }^{[16]}$ whereas iron doping ends up with sites creating oxo species being less active in creating methyl radicals for OCM.

The purpose of the present work was to elucidate much along the demand of Hutchings ${ }^{[17]}$ how electronic promoters may change the reaction pathway of the OCM reaction. Stimulated through the clear-cut model observation of Freund et al. we synthesized a polycrystalline form of model compound exhibiting the same subsurface doping as evidently achieved in the model system of Freund. By carefully avoiding the formation of nanoparticles of the transition metal oxide we observed the predicted doping effect without interference form deep oxidation of the methane molecule.

It was not our intention to explore the potential of this electronic effect with respect to selectivity and yield. We rather wanted to demonstrate by a catalytic experiment that as from chemical physics predicted an electronic doping effect exists for alkali earth oxides affecting oxygen activation. Its amplification by gold being activated through a specific interaction with $\mathrm{MgO}$ at iron-modified sites is an additional benefit. As the doping procedure is reproducible and the levels of doping species are low it is conceivable that the concept of homogeneous electronic doping of alkali earth oxides may find application for stabilization of realistic systems.

\section{Experimental Section}

Detailed information on catalyst synthesis, characterization, and catalytic tests is provided in the Supporting Information.

Received: ((will be filled in by the editorial staff))

Published online on ((will be filled in by the editorial staff))

Keywords: catalysis $\cdot$ alkaline earth oxides $\cdot$ gold $\cdot$ doping $\cdot$ defects

[1] a)H. Schwarz, Angewandte Chemie International Edition 2011, 50, 10096; b)C. Hammond, S. Conrad, I. Hermans, ChemSusChem 2012, 5,1668 . 
[2] U. Zavyalova, M. Holena, R. Schlögl, M. Baerns, ChemCatChem 2011, 3, 1935.

[3] T. Ito, T. Watanabe, T. Tashiro, K. Toi, Journal of the Chemical Society-Faraday Transactions I 1989, 85, 2381.

[4] a)U. Zavyalova, M. Geske, R. Horn, G. Weinberg, W. Frandsen, M. Schuster, R. Schlögl, ChemCatChem 2011, 3, 949-959; b)U.

Zavyalova, G. Weinberg, W. Frandsen, F. Girgsdies, T. Risse, K. P. Dinse, R. Schloegl, R. Horn, ChemCatChem 2011, 3, 1779-1788.

[5] D. Beruto, A. W. Searcy, R. Botter, M. Giordani, The Journal of Physical Chemistry 1993, 97, 9201-9205.

[6] Y. Cui, N. Nilius, X. Shao, M. Baldofski, J. Sauer, H.-J. Freund, Angewandte Chemie 2013, submitted.

[7] J. H. Lunsford, Angewandte Chemie International Edition in English 1995, 34, 970-980

[8] J. S. J. Hargreaves, G. J. Hutchings, R. W. Joyner, C. J. Kiely, Journal of Catalysis 1992, 135, 576-595.

[9] K. Blick, T. D. Mitrelias, J. S. J. Hargreaves, G. J. Hutchings, R. W. Joyner, C. J. Kiely, F. E. Wagner, Catalysis Letters 1998, 50, 211-218.

[10] G. Lehmann, Z. Phys. Chem. Neue Folge 1970, 72, 279-297.
[11] C. F. Bohren, D. R. Huffman, Absorption and Scattering of Light by Small Particles, John Wiley and Sons, New York, 1983.

[12] K. C. Grabar, R. G. Freeman, M. B. Hommer, M. J. Natan, Analytical Chemistry 1995, 67, 735-743

[13] B. V. King, F. Freund, Physical Review B 1984, 29, 5814-5824.

[14] J. S. J. Hargreaves, G. J. Hutchings, R. W. Joyner, C. J. Kiely, Catalysis Today 1992, 13, 401-407.

[15] M. J. Hytch, E. Snoeck, R. Kilaas, Ultramicroscopy 1998, 74, 131.

[16] P. Landon, P. J. Collier, A. J. Papworth, C. J. Kiely, G. J. Hutchings, Chemical Communications 2002, 0, 2058.

[17] G. J. Hutchings, Catalysis Letters 2001, 75, 1. 


\section{Entry for the Table of Contents}

Layout 1:

\section{C-H activation}

Pierre Schwach, Marc Willinger, Annette Trunschke*, and Robert Schlögl

Methane coupling over doped

magnesium oxide: how doping can work

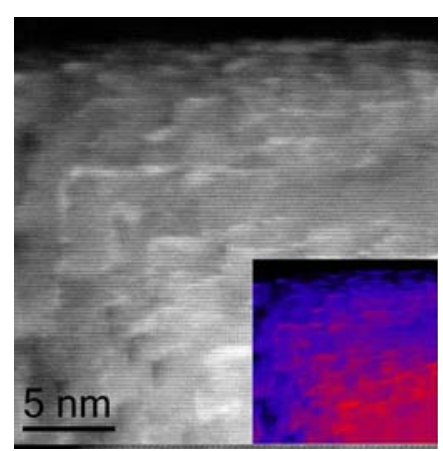

Oxidative coupling of methane over magnesium oxide is affected by electronic doping creating highly active sites by co-modification of $\mathrm{MgO}$ with iron and gold in ppm quantity. 


\title{
Supporting information
}

\section{Methane coupling over magnesium oxide: how doping can work}

\author{
Pierre Schwach, Marc Willinger, Annette Trunschke*, Robert Schlögl
}

\section{Experimental Details}

\subsection{Catalyst synthesis}

Fe-MgO: Two Teflon autoclaves with a volume of $100 \mathrm{~mL}$ were filled each with $3 \mathrm{~g} \mathrm{MgO} \mathrm{(Alfa} \mathrm{Aesar} 99.998 \mathrm{~m} . b$. (ID\#14564, batch number 24686) suspended in $69.5 \mathrm{~mL}$ distilled water. Subsequently, $0.537 \mathrm{~mL}$ of a $0.05 \mathrm{M} \mathrm{FeSO}_{4}$ (Sigma) solution was added. The suspension was heated to $483 \mathrm{~K}$ for 3 hours in a microwave oven (Speedwave MWS-3+, Berghof Products + Instruments $\mathrm{GmbH}$ ) at a pressure of 10 bar. The resulting material was isolated by filtration, washed with distilled water, and dried at $393 \mathrm{~K}$ in air for $12 \mathrm{~h}$. For thermal treatment, the dried product was placed into a quartz crucible, which was located inside a quartz tube, and annealed in flowing $\operatorname{Ar}(150 \mathrm{~mL} / \mathrm{min}$ ) at $1173 \mathrm{~K}$ (heating rate $10 \mathrm{~K} / \mathrm{min}$ ) for 3 hours using a tube furnace (Carbolite). To remove segregated iron oxide particles, the resulting solid was washed in a mixture of $5 \mathrm{~mL} 0.1 \mathrm{M}$ $\mathrm{HNO}_{3}$ and $25 \mathrm{~mL} \mathrm{H}_{2} \mathrm{O}$ by stirring at $293 \mathrm{~K}$ for 1 hour. The washed and dried product was annealed again in flowing $\operatorname{Ar}(150$ $\mathrm{mL} / \mathrm{min}$ ) at $1123 \mathrm{~K}$ (heating rate $5 \mathrm{~K} / \mathrm{min}$ ) for 3 hours.

Au-MgO: Two Teflon autoclaves with a volume of $100 \mathrm{~mL}$ were filled each with $3 \mathrm{~g} \mathrm{MgO}$ (Alfa Aesar 99.998 m.b. (ID\#14564, batch number 24686) suspended in $69.5 \mathrm{~mL}$ distilled water. Subsequently, $0.51 \mathrm{~mL}$ of a $0.015 \mathrm{M} \mathrm{HAuCL}_{4} \cdot \mathrm{xH}_{2} \mathrm{O}$ (Sigma) solution was added. The suspension was heated to $483 \mathrm{~K}$ for 3 hours in a microwave oven (Speedwave MWS-3+, Berghof Products + Instruments $\mathrm{GmbH}$ ) at a pressure of 10 bar. The resulting material was isolated by filtration, washed with distilled water, and dried at $393 \mathrm{~K}$ in air for $12 \mathrm{~h}$. For thermal treatment, the dried product was placed into a quartz crucible, which was located inside a quartz tube, and annealed in flowing $\operatorname{Ar}(150 \mathrm{~mL} / \mathrm{min})$ at $1173 \mathrm{~K}$ (heating rate $10 \mathrm{~K} / \mathrm{min})$ for 3 hours using a tube furnace (Carbolite). To remove segregated Au particles, the resulting solid was washed in a mixture of $5 \mathrm{~mL}$ $0.1 \mathrm{M}$ aqua regia and $25 \mathrm{~mL} \mathrm{H}_{2} \mathrm{O}$ by stirring at $293 \mathrm{~K}$ for 1 hour. The washed and dried product was annealed again in flowing $\operatorname{Ar}(150 \mathrm{~mL} / \mathrm{min})$ at $1123 \mathrm{~K}$ (heating rate $5 \mathrm{~K} / \mathrm{min}$ ) for 3 hours. The resulting catalyst was stored under argon and freshly pretreated before analysis or catalysis.

Au-Fe-MgO: Two Teflon autoclaves with a volume of $100 \mathrm{~mL}$ were filled each with $3 \mathrm{~g} \mathrm{MgO}$ (Alfa Aesar 99.998 m.b. (ID\#14564, batch number 24686) suspended in $69 \mathrm{~mL}$ distilled water. Subsequently, $0.508 \mathrm{~mL}$ of a $0.015 \mathrm{M} \mathrm{HAuCL}_{4} \cdot \mathrm{xH}_{2} \mathrm{O}$ (Sigma) solution, and $0.538 \mathrm{~mL}$ of $0.05 \mathrm{M} \mathrm{FeSO}_{4}$ (Sigma) solution were added. The suspension was heated to $483 \mathrm{~K}$ for 3 hours in a microwave oven (Speedwave MWS-3+, Berghof Products + Instruments GmbH) at a pressure of 10 bar. The resulting material was isolated by filtration, washed with distilled water, and dried at $393 \mathrm{~K}$ in air for $12 \mathrm{~h}$. For thermal treatment, the dried product was placed into a quartz crucible, which was located inside a quartz tube, and annealed in flowing $\operatorname{Ar}(150 \mathrm{~mL} / \mathrm{min})$ at $1173 \mathrm{~K}$ (heating rate $10 \mathrm{~K} / \mathrm{min}$ ) for 3 hours using a tube furnace (Carbolite). To remove segregated iron oxide and Au particles, the resulting solid was washed in a mixture of $10 \mathrm{~mL} 0.1 \mathrm{M}$ aqua regia and $20 \mathrm{~mL} \mathrm{H}_{2} \mathrm{O}$ by stirring at $293 \mathrm{~K}$ for 1 hour. The washed and dried product was annealed again in flowing $\mathrm{Ar}(150 \mathrm{~mL} / \mathrm{min})$ at $1123 \mathrm{~K}$ (heating rate 5 $\mathrm{K} / \mathrm{min}$ ) for 3 hours. The resulting catalyst was stored under argon and freshly pre-treated before analysis or catalysis.

The resulting catalysts were stored under argon and freshly pre-treated before analysis or catalysis.

\section{2. $X$-ray diffraction}

XRD was measured on a STOE STADI-P transmission diffractometer with a focusing primary Ge(111) monochromator and a linear PSD applying $\mathrm{Cu} \mathrm{K}_{\alpha 1}$ radiation $(\lambda=1.5406 \AA)$.

The XRD data were analyzed by full pattern fitting using the TOPAS software (version 3, copyright 1999, 200 Bruker AXS).

\subsection{Nitrogen adsorption}

The surface area determination was carried out in a volumetric $\mathrm{N}_{2}$ physisorption set-up (Autosorb-6-B, Quantachrome) at the temperature of liquid nitrogen. The sample was degassed in dynamic vacuum at a temperature of $473 \mathrm{~K}$ for $2 \mathrm{~h}$ prior to adsorption. The relative $\mathrm{N}_{2}$ pressure was varied $\left(\mathrm{p} / \mathrm{p}_{0}=0.05-0.3\right)$, and 11 data points were measured. The linear range of the adsorption isotherm was considered to calculate the specific surface area according to the BET method.

\subsection{Atomic Absorption Spectroscopy (AAS)}

The iron content was determined by Atomic Absorption Spectroscopy (AAS). Experiments were performed on a Perkin Elmer AAS 4100 spectrometer using a $\mathrm{N}_{2} \mathrm{O}$-acetylene flame and a wavelength of $271.9 \mathrm{~nm} .250 \mathrm{mg}$ of the catalyst were dissolved in 
$25 \mathrm{~mL} \mathrm{HNO}_{3}\left(65 \%\right.$ p.a.) and backfilled to $250 \mathrm{~mL}$ with distilled $\mathrm{H}_{2} \mathrm{O}$. Zero, 50 and $100 \mu \mathrm{g}$ iron were added to $25 \mathrm{~mL}$ of this solution, respectively, and backfilled to $50 \mathrm{~mL}$ with a solution of $5 \% \mathrm{HNO}_{3}$ in water.

\subsection{Diffuse reflectance spectroscopy (DRS)}

The in situ UV-VIS experiments were performed in the range between 200 and $800 \mathrm{~nm}$ using a Perkin Elmer Lambda 650 spectrometer equipped with a diffuse reflectance accessory (Praying Mantis, Harrick) complete with an environmental chamber attachment (Harrick HVC-VUV-4) using Spectralon ${ }^{\circledR}$ as white standard. The catalysts were pretreated in situ at 923 $\mathrm{K}$ for $30 \mathrm{~min}$ in flowing $\operatorname{Ar}(20 \mathrm{~mL} / \mathrm{min})$, and measured in the same argon flow at room temperature.

\subsection{Electron Paramagnetic Resonance (EPR)}

EPR spectra were recorded at liquid nitrogen temperature on a Bruker ESR $300 \mathrm{E}$ spectrometer equipped with a microwave bridge Bruker ER 042 MRH E. A Bruker ER 4116 DM resonator operating in the TE 102 mode (resonance frequency $\approx 9.5$ $\mathrm{GHz}$ ) was used. The spectra were recorded with a modulation frequency of $100 \mathrm{kHz}$ and a microwave power of $2 \mathrm{~mW}$. The frequency and $\mathrm{g}$ values were calibrated using the signal of $\mathrm{Mn}^{2+}$ ions $(g=2.0007, A=-244 \mathrm{MHz}, a=55 \mathrm{MHz})^{[\mathrm{Sla}]}$ present as impurity in $\mathrm{MgO}$ (3 ppm as determined by ICP-OES analysis) A small signal assigned to $\mathrm{Cr}^{3+}$ can also be observed with a $\mathrm{g}$ tensor of $1.98\left(0.2 \mathrm{ppm}\right.$ as determined by ICP-OES analysis). ${ }^{[\mathrm{S} 1 \mathrm{~b}]}$ The samples were placed in a quartz cell equipped with Teflon Duran ${ }^{\circledR}$ valves and connected to a vacuum system that allows the dosing of gases. Before the EPR measurements, the $\mathrm{MgO}$ samples were activated at $1073 \mathrm{~K}$ under dynamic vacuum $\left(10^{-6}-10^{-7} \mathrm{mbar}\right)$ for 3 hours.

[S1] a) W. Low, Physical Review 1957, 105, 793-800; b) S. Eidels-Dubovich, V. Beltran-Lopez, J. Magnet. Res. 1987, 74, 94-104.

\subsection{Temperature-Programmed-Reduction-Oxidation (TPR-O) experiments}

Temperature-programmed oxidation and reduction experiments were performed in a fixed-bed quartz reactor placed inside a tube furnace (Carbolite). The position of the catalyst inside the reactor was fixed applying a frit. The temperature was measured in the catalyst bed using a thermocouple (K-type). The feed was composed of $0.5 \% \mathrm{O}_{2}$ or $\mathrm{H}_{2}$, respectively, in $\mathrm{He}$ and $\mathrm{Ar}$, respectively. A flow rate of $90 \mathrm{~mL} \cdot \mathrm{min}^{-1}$ was applied. A mass of $600 \mathrm{mg}$ of the catalyst with a $200-300 \mu \mathrm{m}$ sieved fraction was used and diluted with $3 \mathrm{~g} \mathrm{SiC}$ in order to improve the thermal conductivity in the catalyst bed. The measurements were performed applying a heating rate of $10 \mathrm{~K} \cdot \mathrm{min}^{-1}$. Hydrogen concentration in the gas phase was analyzed using a TCD detector (Rosemount Analytical) after the off-gas passed a molecular sieve trap to remove water. Before measurements, the catalysts were pretreated in $90 \mathrm{~mL} \cdot \mathrm{min}^{-1} \mathrm{Ar}$ at $1073 \mathrm{~K}$ with a heating rate of $10 \mathrm{~K} \cdot \mathrm{min}^{-1}$ for $1 \mathrm{~h}$ to remove adsorbed water molecules and other adsorbates.

\subsection{Catalytic measurements}

The catalytic measurements were carried out in a laboratory quartz U-tube fixed bed reactor $(4 \mathrm{~mm}$ inner diameter, $6 \mathrm{~mm}$ outer diameter, $26 \mathrm{~cm}$ length) applying reaction conditions as indicated in the main text. Gas analysis was performed by online gas chromatography (GC 6890A, Agilent). Nitrogen was used as internal standard to account for volume effects due to the high temperature.

\subsection{Electron microscopy}

Electron microscopy was carried out using a Cs-corrected FEI Titan 80-300 instrument operating at $300 \mathrm{kV}$ in bright field high-resolution transmission electron microscopy (HRTEM) and high angle annular dark field scanning transmission electron microscopy (HAADF STEM) mode, respectively. 


\section{Diffuse reflectance spectroscopy}

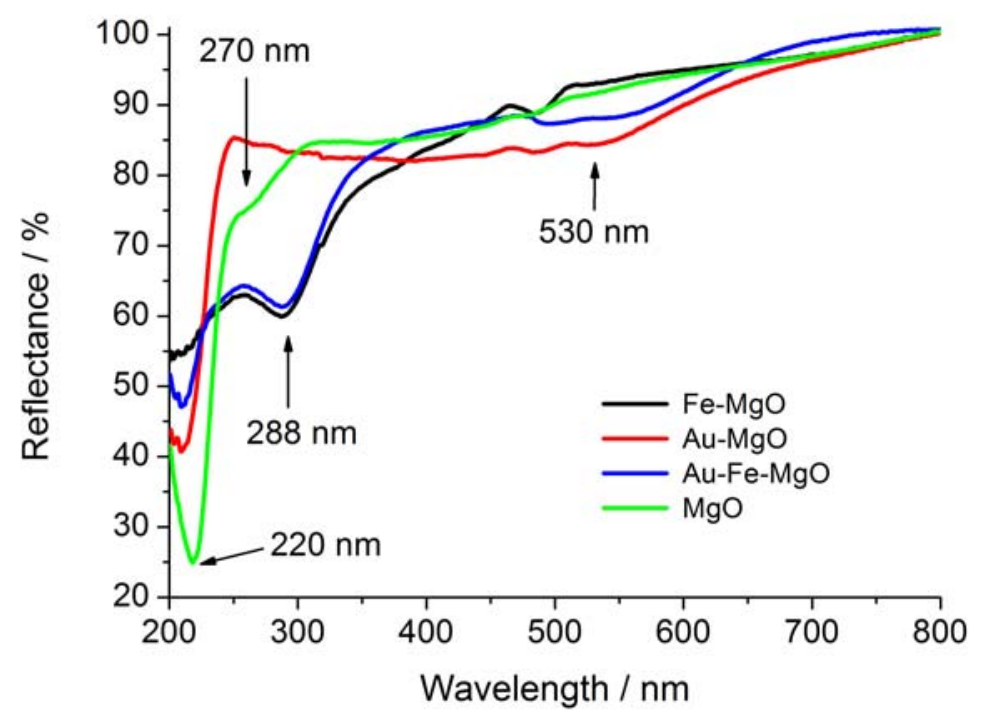

Fig. S1. UV-vis spectra of the doped catalysts measured in Ar at $293 \mathrm{~K}$ after pretreatment in Ar at $923 \mathrm{~K}$.

\section{EPR spectroscopy}
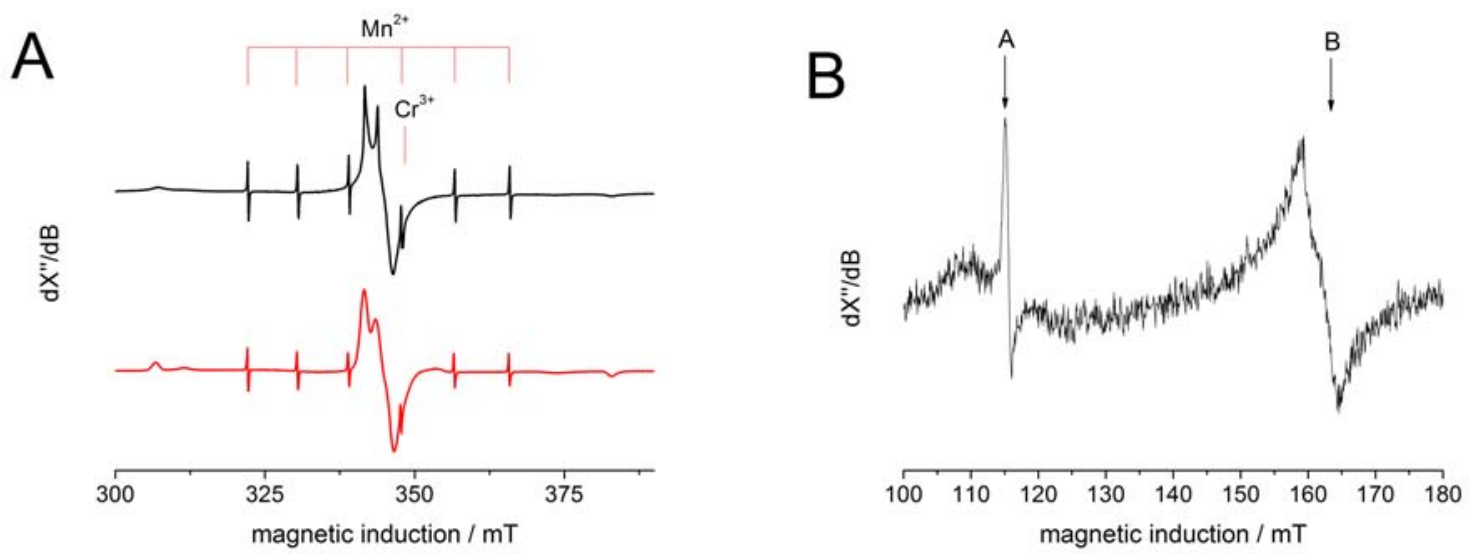

Fig. S2. EPR spectrum of Au-Fe-MgO after pretreatment at $1073 \mathrm{~K}$ under high vacuum, measured at $77 \mathrm{~K}$, A) Experimental (black line) and simulated ${ }^{[\mathrm{S} 2]}$ spectrum (red line). B) Experimental spectra of $\mathrm{Fe}^{3+}$ at lower magnetic field. Both spectra are measured at a frequency of $9.63637 \mathrm{GHz}$.

The experimental signal (Fig. S2 A, black line) at $\mathrm{g}=2.0037$ is attributed to $\mathrm{Fe}^{3+}$ ions present in a cubic symmetry field, ${ }^{[\mathrm{S} 3]}$ which is also well reflected by the simulation of the spectrum $(\mathrm{g}=2.0037, \mathrm{a}=640 \mathrm{MHz}, \mathrm{wpp}=1 \mathrm{mT}$, and $\mathrm{D}=-100 \mathrm{MHz}) \mathrm{using}$ the Easyspin package in MATLAB. ${ }^{[\mathrm{S} 2]}$ The species A and B at low fields (Fig. S2 B) are assigned to Fe ${ }^{3+}$ ions in a coordination geometry of lower symmetry. These signals are usually assigned to $\mathrm{Fe}^{3+}$ in orthorhombic or tetragonal symmetry sites in $\mathrm{MgO} \cdot{ }^{[\mathrm{S} 4]}$ No sign of point defect can be found in the Au-Fe-MgO sample by EPR. ${ }^{[\mathrm{S} 5]}$

[S2] S. Stoll, A. Schweiger, Journal of Magnetic Resonance 2006, 178, 42-55.

[S3] aV. Beltrán-López, J. Castro-Tello, Journal of Magnetic Resonance (1969) 1980, 39, 437-460; bJ. H. Lunsford, The Journal of Chemical Physics 1965, 42, 2617-2618.

[S4] J. T. Castner, G. S. Newell, W. C. Holton, C. P. Slichter, The Journal of Chemical Physics 1960, 32, $668-673$.

[S5] a) R. S. d. Biasi, Journal of Physics C: Solid State Physics 1981, 14, 4885; b) R. S. De Biasi, A. Caldas, J. Phys. C: Solid State Phys. 1977, 10, 107-111. 


\section{Temperature-programmed-reduction-oxidation (TPR-TPO)}

Table S1: Hydrogen consumption in TPR $\left(\mathrm{H}_{2}\right.$ evolution during activation (negative values)).

\begin{tabular}{|c|c|c|}
\hline & $\begin{array}{l}\text { Hydrogen consumption } \\
\text { (evolution) } / \mu \mathrm{mol}\left(\mathrm{H}_{2}\right) /\left(\mathrm{s} \cdot \mathrm{g}_{\text {cat }}\right)\end{array}$ & Fraction of total $\mathrm{Fe} / \%$ \\
\hline \multicolumn{3}{|c|}{ Fe content*: $7.20 \mu \mathrm{mol} / \mathrm{g}$} \\
\hline Activation & -0.25 & - \\
\hline TPR1 & 0.13 & 1.8 \\
\hline TPR2 & 0.48 & 6.7 \\
\hline TPR3 & 0.48 & 6.7 \\
\hline \multicolumn{3}{|c|}{ Fe content*: $11.71 \mu \mathrm{mol} / \mathrm{g}$} \\
\hline Activation & -0.56 & - \\
\hline TPR1 & 0.81 & 6.9 \\
\hline TPR2 & 0.75 & 6.4 \\
\hline TPR3 & 0.74 & 6.3 \\
\hline
\end{tabular}

* Analyzed by AAS. 


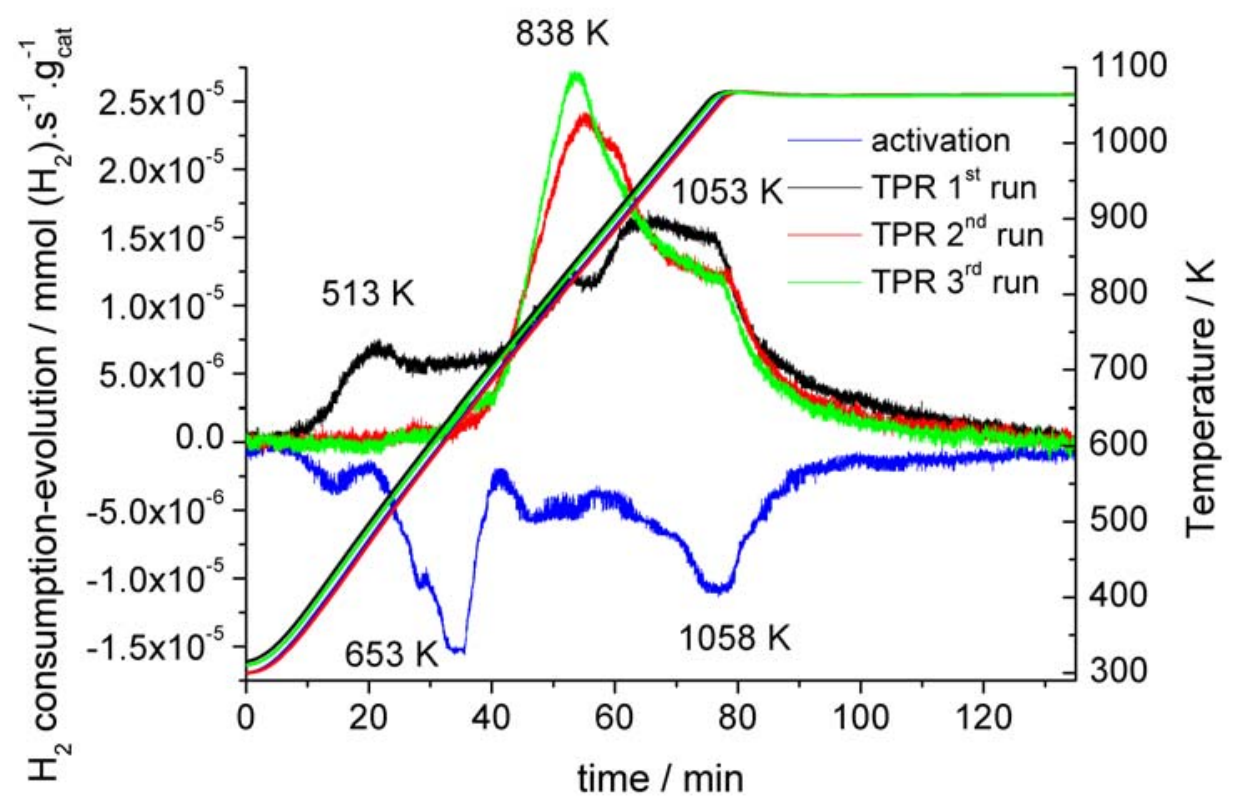

Fig. S3. TPR-O of Fe-MgO. The blue line was measured during pretreatment in $90 \mathrm{~mL} \cdot \mathrm{min}^{-1}$ Ar applying a heating rate of 10 $\mathrm{K} \cdot \mathrm{min}^{-1}$.

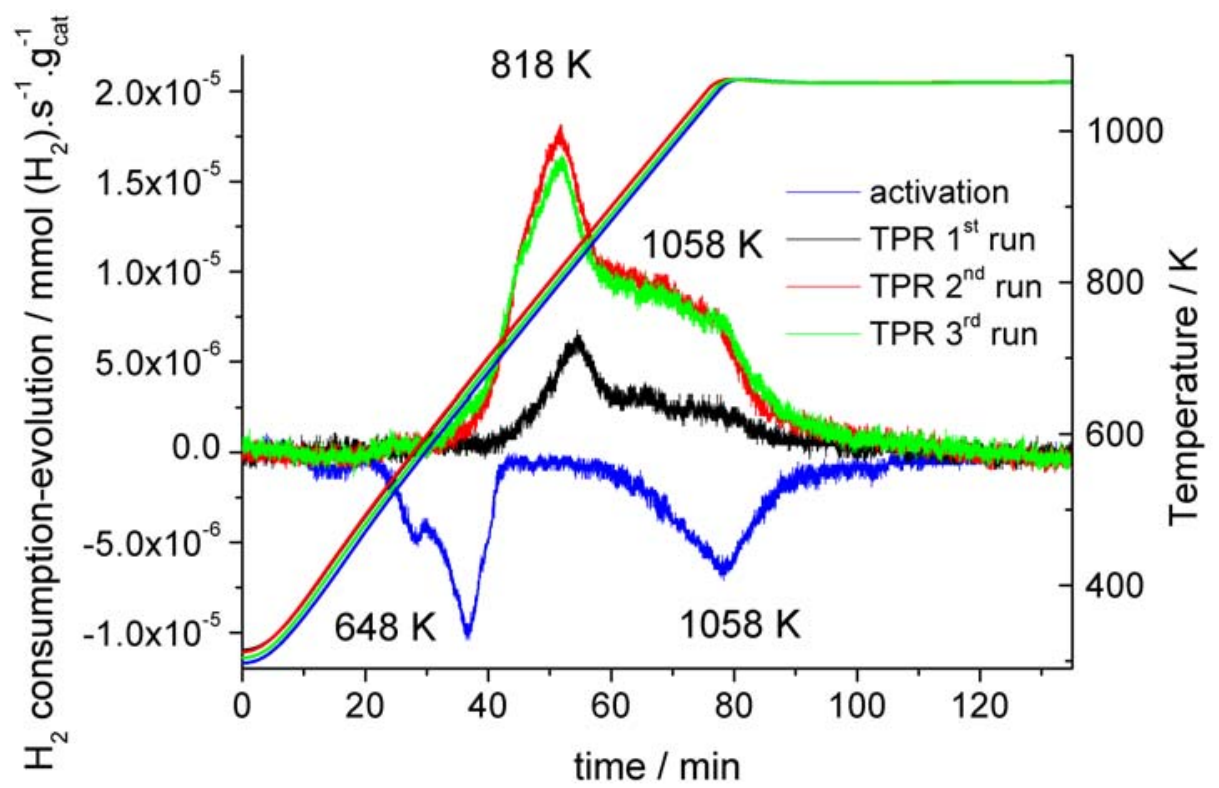

Fig. S4. TPR-O of Au-Fe-MgO. The blue line was measured during pretreatment in $90 \mathrm{~mL} \cdot \mathrm{min}^{-1}$ Ar applying a heating rate of $10 \mathrm{~K} \cdot \mathrm{min}^{-1}$. 


\section{Oxidative coupling of methane}

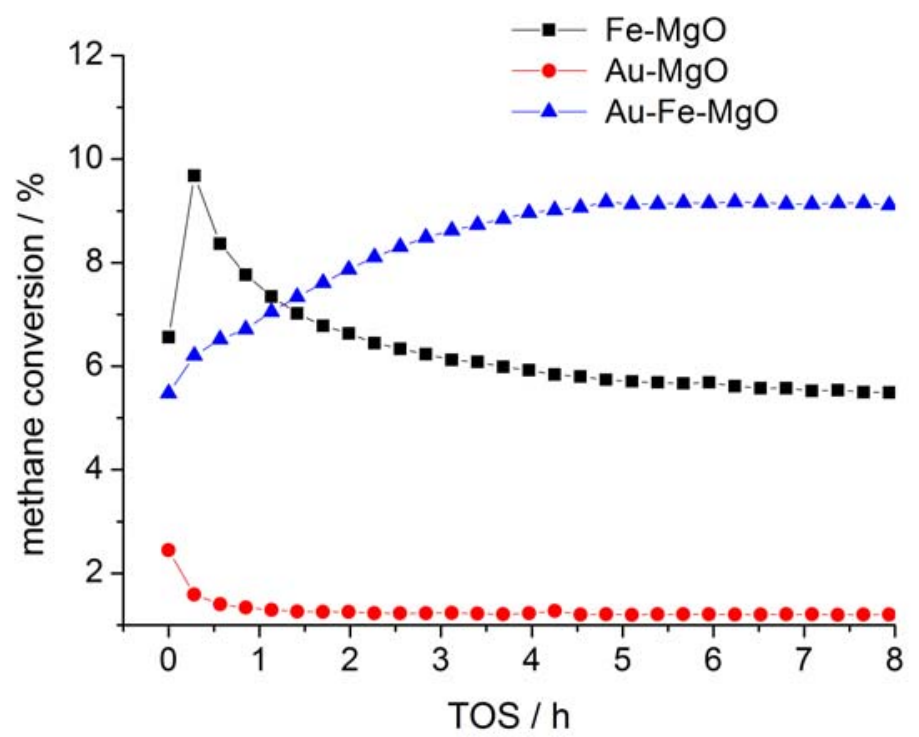

Fig. S5 Methane conversion in the oxidative coupling of methane as a function of time on stream $(\mathrm{TOS})$ at $\mathrm{T}=1023 \mathrm{~K}$; W/F= $0.0167 \mathrm{~g} \cdot \mathrm{s} \cdot \mathrm{ml}^{-1} ; \mathrm{CH}_{4} / \mathrm{O}_{2} / \mathrm{N}_{2}=3 / 1 / 1$.

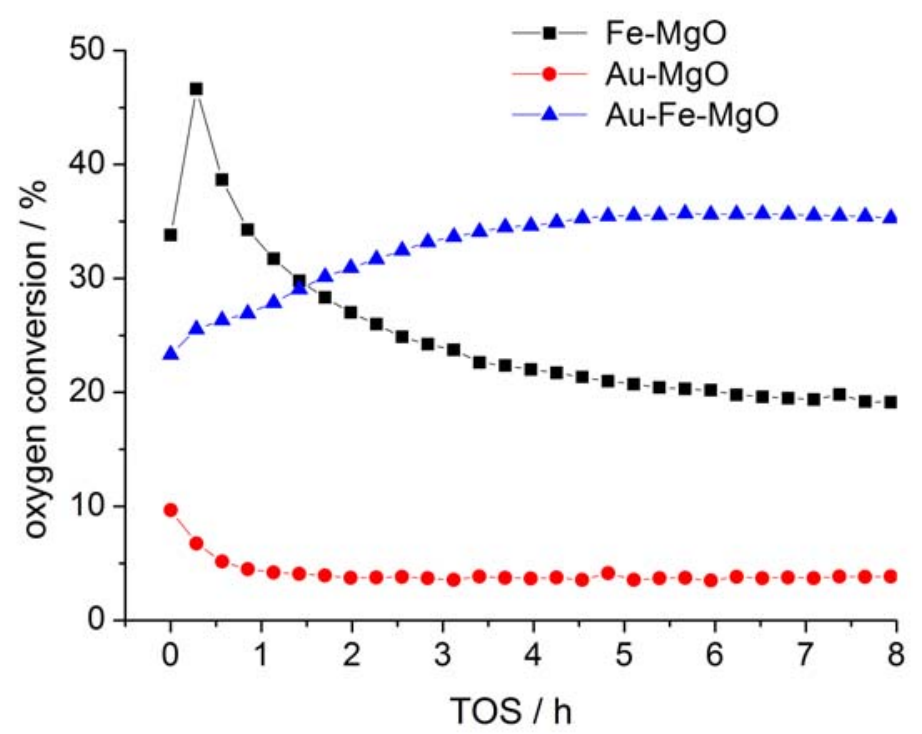

Fig. S6 Oxygen conversion in the oxidative coupling of methane as a function of time on stream $(\mathrm{TOS})$ at $\mathrm{T}=1023 \mathrm{~K} ; \mathrm{W} / \mathrm{F}=$ $0.0167 \mathrm{~g} \cdot \mathrm{s} \cdot \mathrm{ml}^{-1} ; \mathrm{CH}_{4} / \mathrm{O}_{2} / \mathrm{N}_{2}=3 / 1 / 1$. 


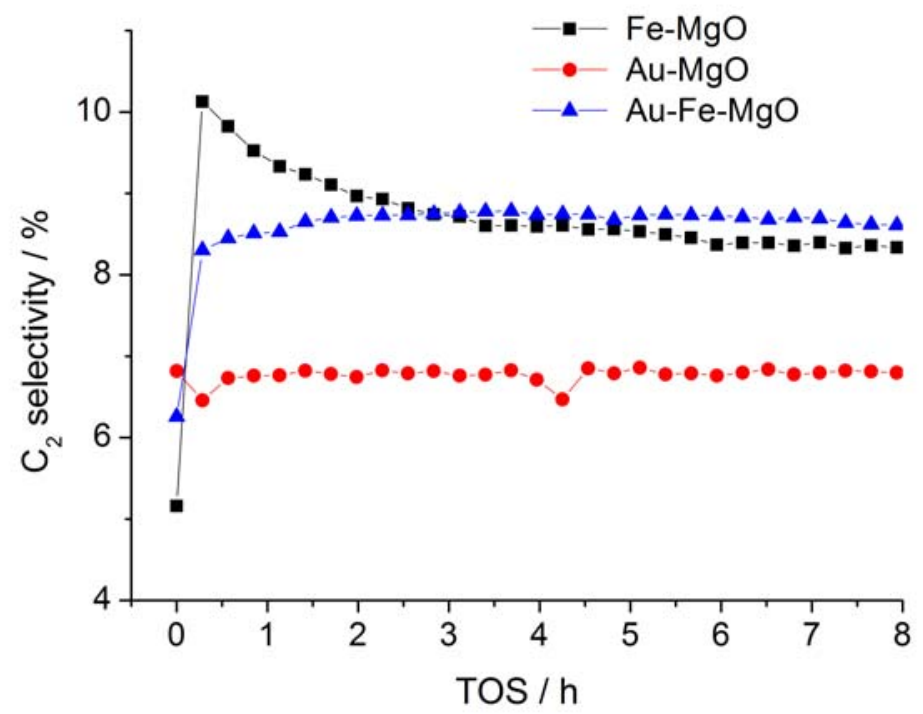

Fig. S7 Selectivity of the sum of ethane and ethene $\left(\mathrm{C}_{2}\right)$ in the oxidative coupling of methane as a function of time on stream (TOS) at $\mathrm{T}=1023 \mathrm{~K} ; \mathrm{W} / \mathrm{F}=0.0167 \mathrm{~g} \cdot \mathrm{s} \cdot \mathrm{ml}^{-1} ; \mathrm{CH}_{4} / \mathrm{O}_{2} / \mathrm{N}_{2}=3 / 1 / 1$.

\section{Electron microscopy}

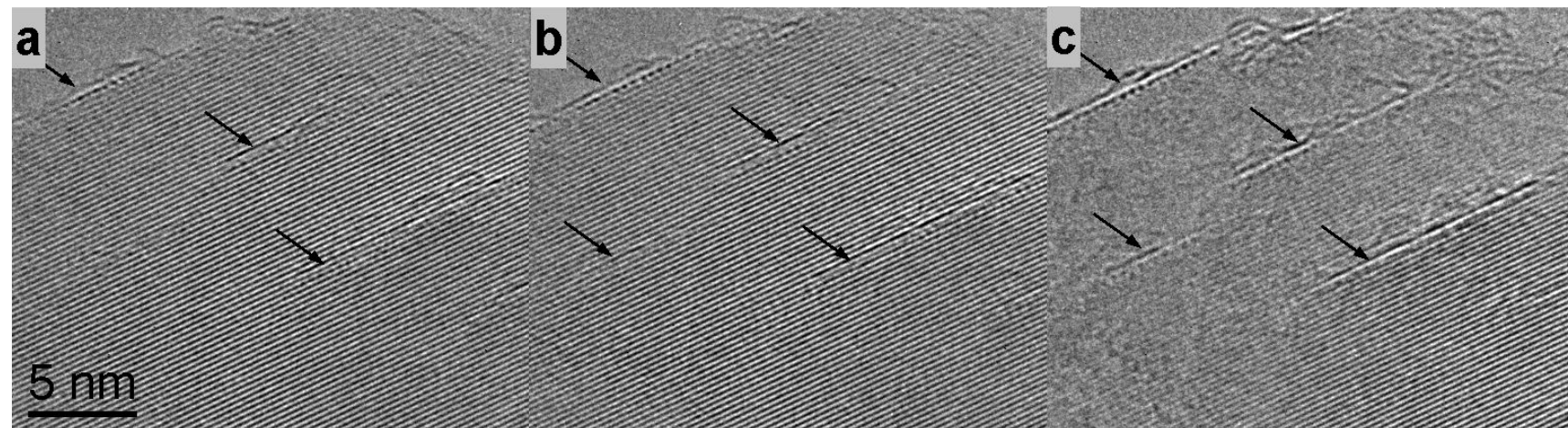

Fig. S8. Series of HRTEM images recorded at different defocus reveal the presence of strongly scattering atoms located at the steps in the Au-Fe-MgO catalyst after catalysis. 